\title{
Preliminary Design of High-Rise Building's Techniques
}

\section{Lovneesh Sharma, Swati Pathak}

\begin{abstract}
The development of tall structures has recently been restricted in India. Changes in the public arena as of late, identified with urbanization, financial aspects and compositional guidelines have anyway brought about a more prominent enthusiasm for the development of elevated structures. When planning elevated structures, challenges are confronted which frequently can be slighted when planning lower structures. In this paper, a procedure which can be utilized in the primer structure procedure of tall structures is created. The philosophy depends on romanticized estimation models The work is centered around structures with an auxiliary framework comprising of a solid center with the likelihood of including outriggers. The paper likewise features the diverse marvels identified with tall structures that should be considered in the starter arrange, or later, in the plan procedure.
\end{abstract}

Keywords: High rise building, Shear wall, Bracings, Preliminary Design Process

\section{INTRODUCTION}

The high buildings can be defined in many ways, if the building height is greater than the maximum firefighting equipment it can be called as high rise building because of fire regulations [1]. When structuring tall structures, challenges are confronted which regularly can be dismissed when planning lower structures? These may incorporate torsion of the structure and influencing because of dynamic burdens. Because of the absence of tall structures in Sweden, the information of how to manage these issues is restricted. This paper spread the means to make in the fundamental plan, when diverse alternatives for basic frameworks are considered and unpleasant measurements are chosen. The investigation demonstrates that an admired pillar model of the structure with changing firmness will give adequate outcomes for the starter plan.

\section{HIGH-RISE BUILDINGS}

\section{Structural design process}

There are a wide range of approaches to characterize what an elevated structure.

Revised Manuscript Received on April 25, 2020.

* Correspondence Author

Lovneesh Sharma*, Research Scholar, Civil Engineering Department, Chandigarh University Gharaun , Mohali (Punjab), India.

Swati Pathak, Mtech, Civil Engineering Department, Shimla University, Shimla (H.P) India

(C) The Authors. Published by Blue Eyes Intelligence Engineering and Sciences Publication (BEIESP). This is an open access article under the CC BY-NC-ND license (http://creativecommons.org/licenses/by-nc-nd/4.0/)
A city organizer will frequently characterize it as a structure that obviously juts over the encompassing structures. On the off chance that the tallness of the structure bigly affects the departure or if the stature of the structure is more prominent than the most extreme reach of firefighting gear it tends to be known as an elevated structure due to flame guidelines. A structure is then frequently considered a tall structure when dynamic burdens ends up significant. By and large terms, an adaptable structure can be thought to be influenced by powerful loads while an inflexible structure is accepted not to. The criteria for an unbending/rigid structure is when the fundamental frequency of the structure is under $1 \mathrm{HZ}$ [2].

\section{STRUCTURAL SYSTEMS}

\section{Rigid frames}

For structures with a genuinely low stature, an unbending edge can be utilized. An unbending edge comprises of segments and braces with minute opposing associations. It opposes sidelong loads with the bowing opposition of the segments and shafts. When structuring structures with minute opposing casings, the span of the sections and bars are regularly constrained by the twisting firmness and not by the heap limit. The high twisting firmness is expected to constrain the float because of horizontal burdens [3]. Moreover the conduct of the structure relies upon the plan of the associations, if a major turn between the pillar and segment is permitted, the horizontal influence of the structure will expand quickly and cause issue with the solace in the structure. Steel or cement can be utilized for this sort of framework. For steel, the most extreme proper stature is around thirty stories and for cement around twenty stories.

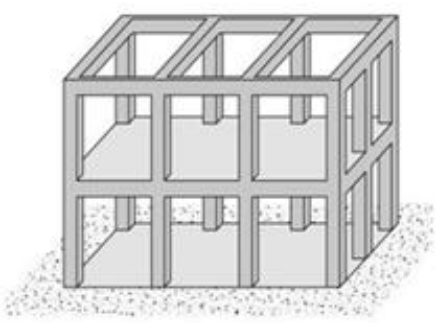

Figure 1: Rigid frame [4]

II. Shear walls

Shear dividers have a high opposition in their very own plane and are utilized to oppose parallel burdens. Shear dividers can oppose toppling minutes, shear powers and furthermore torsion on the off chance that they are appropriately set in the structure. Shear dividers can be utilized in various courses in figure 3. By associating shear dividers a coupled shear divider is gotten. The dividers are coupled by putting pillars between the shear dividers as appeared in figure 4.

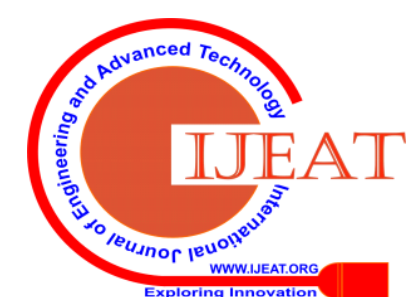




\section{Preliminary Design of High-Rise Building's Techniques}

This is a successful method to incredibly expand the parallel solidness of a structure, this sort of framework is powerful up to 40 storey [2].

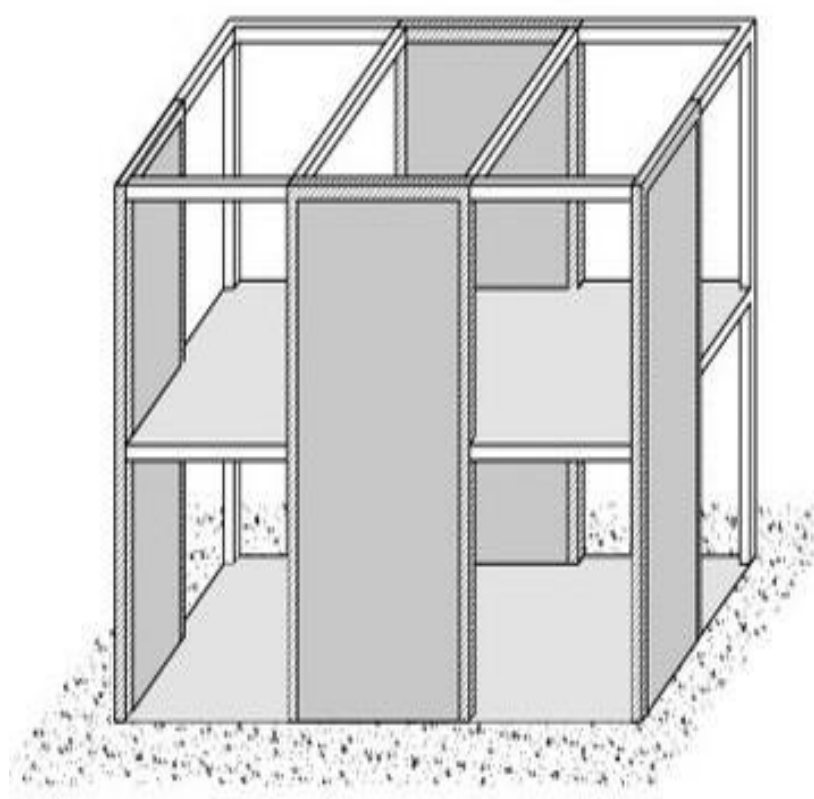

Figure 2: Shear wall [4].
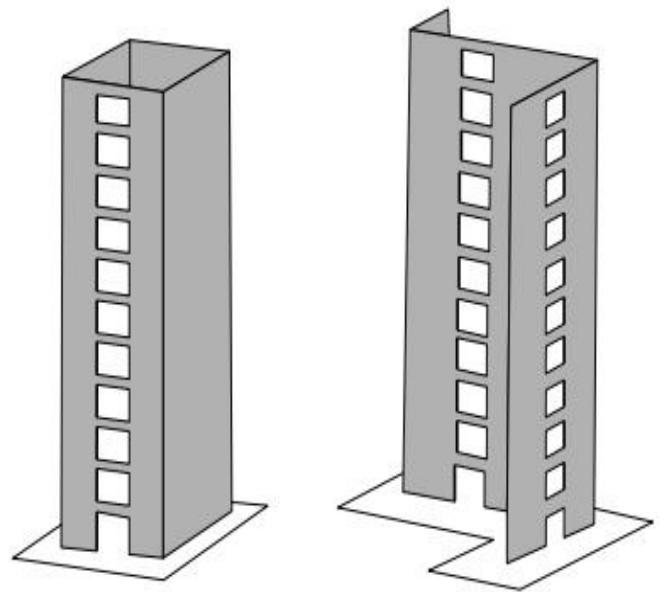

Figure 3: Coupled shear walls [2]

\section{CORE AND OUTRIGGER SYSTEMS}

The center can restrict parallel, vertical and torsion loads. This system is effective up to 45 stories. Additional vertical weights are taken by fragments [2]. Focus can be enhanced with an outrigger structure to inconceivably manufacture its bowing solidness. The outrigger itself involves solidified floors high up in the structure. The robustness can for example be made with dividers, several accounts high[2]. These outriggers are related with areas that reach out along the edge of the structure to the virus earth. At the point when the structure is exposed to parallel burdens they are opposed with pivotal powers in the outside sections and the minute in the center is diminished Outriggers will decrease the horizontal removals of the structure because of bowing.

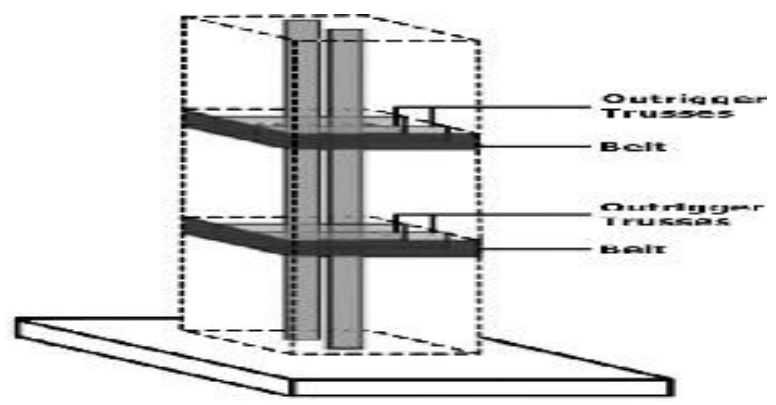

Figure 4: Outrigger system [5].

\section{BRACED FRAMES}

Corner to corner supports can be an enhancement to an unbending edge so as to make a progressively inflexible structure. Supported frameworks lessen the huge shear racking distortions by diminishing bowing of braces and segments. Slanting individuals are put inside the casings which convey sidelong loads and thusly diminishes twisting of pillars and sections. Propped outline frameworks are frequently more efficient than minute opposing casings. The supported edges are frequently put in the center of the structure. Contingent upon the extent of the center, the torsional obstruction might be the controlling structure parameter. The propped casing framework is utilized in steel structures and is compelling up to 40 stories. Two kinds of propped outline frameworks, concentric supported edges (CDF) or unpredictable supported edges (EDF). In the concentric propped outlines, a significant number of the individuals meet in a typical point.
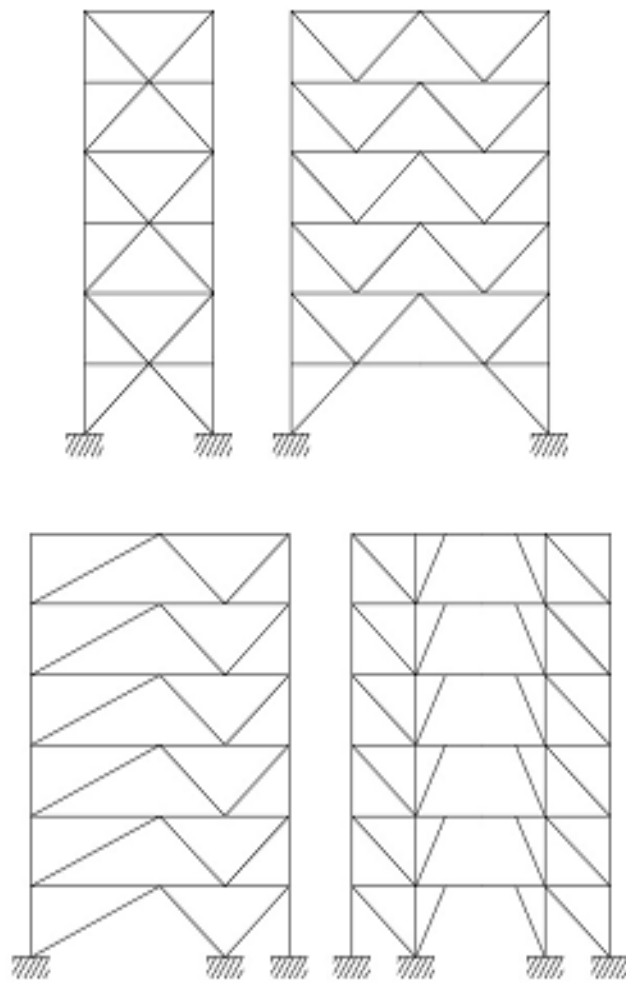

Figure 5: Concentric braced frames[2].

Published By:

Blue Eyes Intelligence Engineering \& Sciences Publication 


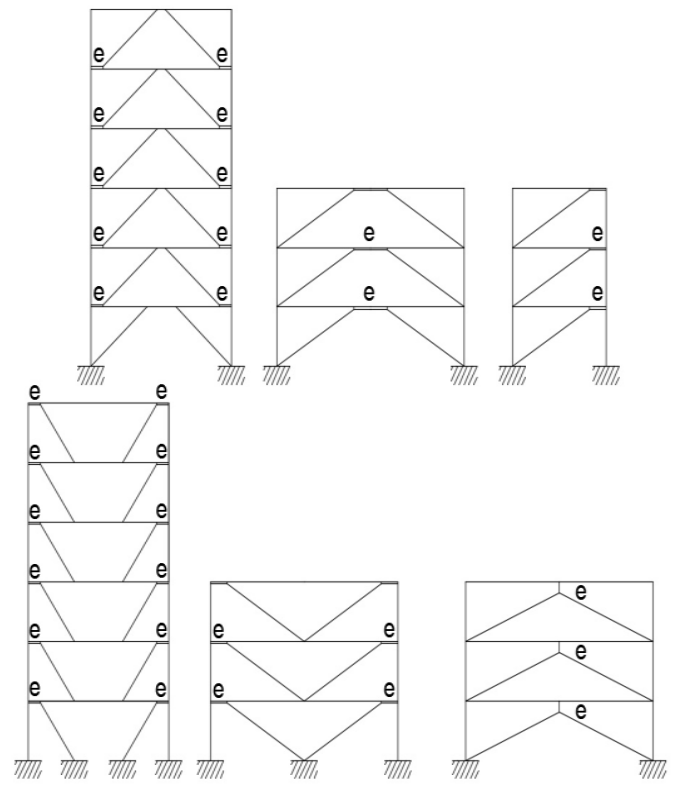

Figure 6: Eccentric braced frames

\section{CHALLENGES RELATED TO HIGH RISE BUILDINGS}

\section{A. Natural frequencies}

The three first regular frequencies for a structure are typically the influence in the two bearings ( $\mathrm{x}$-and $\mathrm{y}$-heading) and the torsional influence (around the z-pivot). Ordinarily, computation of the regular frequencies is made by a PC program which can deal with the eigen esteem examination. Some essential angles to consider while computing the characteristic recurrence are the mass appropriation and the firmness. The mass and firmness at each floor are required. The damping proportion depicts how the swaying of the structure rots after it has been irritated. As of now there is no chance to get of registering the damping proportion of a structure, an esteem is picked dependent on experience[6].
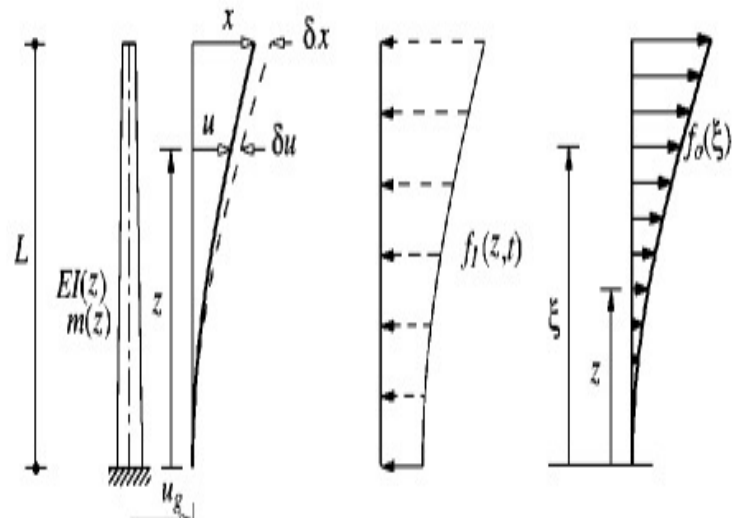

Figure 7: Displacement in building when subjected to a UDL

\section{B. P-DELTAEFFECT}

In tall structures, the P-delta impact can bigly affect the upsetting minute. The P-delta impact is a second request impact and is brought about by the hub constrain and the uprooting of the structure. When planning elevated structures in seismic zones this impact is of considerably more noteworthy significance because of the influencing of the structures. In the event that the influencing of the structure is vast and therefore makes an extensive removal, the upsetting minute could make harm the structure. To stay away from harm or breakdown because of the P-delta impact, the sidelong solidness or the quality of the structure must be expanded [7].
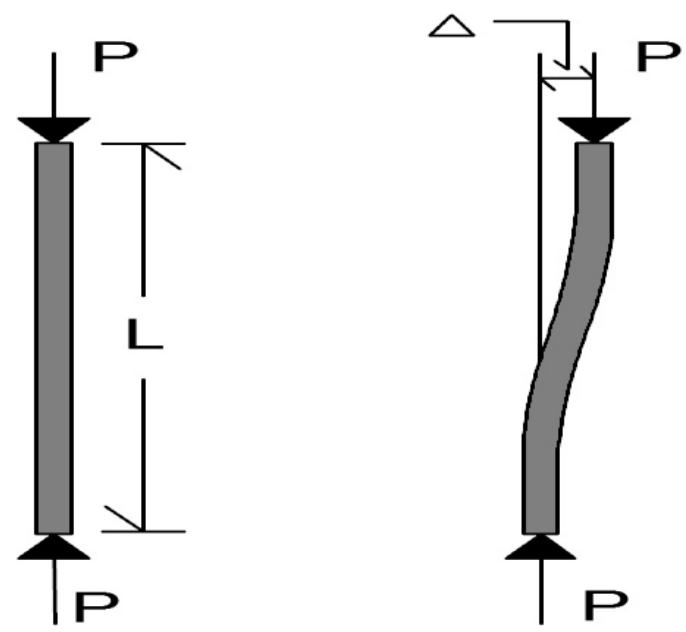

Figure 8: $P$ delta effect [8]

\section{SOFT STOREY COLLAPSE}

Tall structures regularly have less dividers in the base floors to make progressively open spaces, thus lower firmness in contrast with higher up in the structure. Sidelong loads can make the primary and story breakdown while the remainder of the structure opposes the heaps and stays standing.
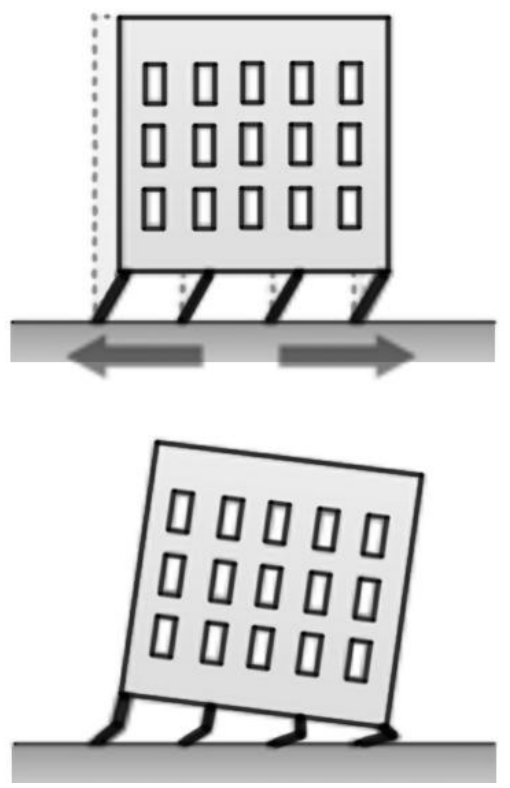

Figure 9: Soft story collapse [9]

\section{DAMPING}

A framework can, contingent upon the measure of damping, be named underdamped, fundamentally damped or overdamped. In figure three bends have been plotted to demonstrate the conduct of the distinctive frameworks after an underlying relocation. An underdamped framework will waver before grinding to a halt. All structures are underdamped and the basic damping is essentially identified with the structure material of the basic framework, the basic damping is for the most part $\zeta=0.1$ or underneath[10].

Published By:

Blue Eyes Intelligence Engineering

\& Sciences Publication

(C) Copyright: All rights reserved.

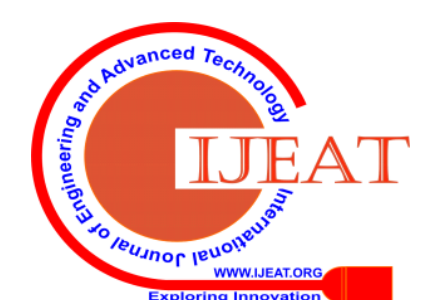




\section{Preliminary Design of High-Rise Building's Techniques}

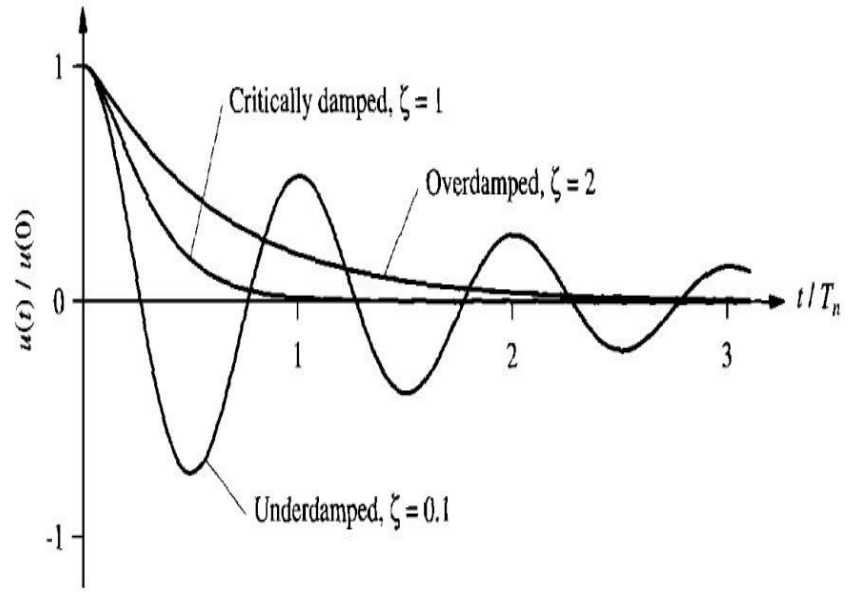

Figure 10: Graph of damping [10]

\section{CALCULATION METHODOLOGY}

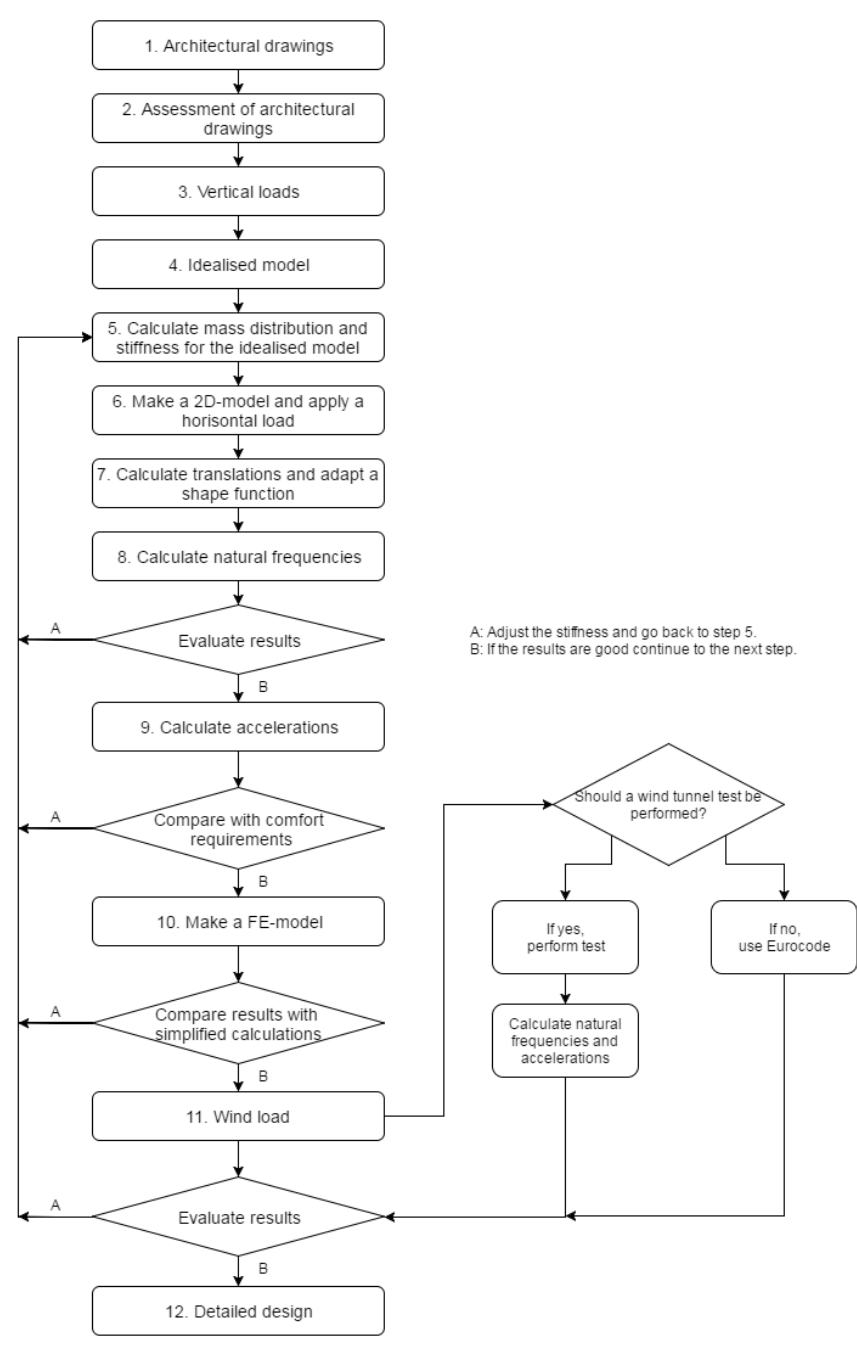

\section{CONCLUSION}

The approach introduced in the paper demonstrates an extremely disentangled technique that can be utilized in the primer plan process. To make an admired pillar model of the structure with fluctuating firmness will give adequate outcomes for the fundamental plan. To figure avoidance shapes, there is an insignificant distinction between utilizing a consistently disseminated burden. To associate the fundamental structure to a lower side-building will have a perceptible effect on the solidness, anyway the situation of the side-building will influence the firmness. For this situation the side-building changed the solidness $21 \%$ on the off chance that it was set opposite to the fundamental structure.

\section{REFERENCES}

1. G. Graighead., 2016, High Rise Security and fire safety, Butterworth-Heinemann.

2. B. S. Taranath., 2010, Reinforced concrete design of tall buildings, CRC Press.

3. M. Halis., H. Emrellgin., 2006, Aproposal for the classification of structural systems of tall buildings and Environment, 42(7): 2667-2675.

4. Moment frame.

http://www.nexus.globalquakemodel,org/gem-buildingm taxonomy/overview/glossary/moment-frame- $1 \mathrm{fm}$ [accessed 2016-03021].

5. S. Fawzia., T. Fatima., 2010, Deection control in composite building by using belt trussand outriggers system, International Journal of Civil Engineering, Environmental, structural engineering, 4(12): 214-419.

6. B. S. Taranath., 2012, Structural Analysis and design of tall buildings; steel and composite construction, CRC Press.

7. B. J. Davidson., R.C. Fenwick., B. T. Chung., 1992, P delta effects in multi-storey structural design in Earthquake Engineering. Tenth World conference, PP-3847-3852, Balkema, Roterdam.

8. What is P delta analysis? http:/risa.com/news/what is p delts-analysisrisatech-risa3d [accessed:2016-02-22]

9. T. Oleson., Facking quakes at full scales: Giant shake tables simulate earthquakes to make buildings safer. http:/www. Earthmagazine.org/article/faking-quakes-full-scale-giant-shake-tables -simulate-safer [accessed: 26-05-13]

10. A. K. Chopra., 2004, Dynamics of structures- Theory and applications to earthquake Engineering Pretice-Hall.

11. Himaja S. V. G., Ashwini L. K., Jayaramappa N., 2015, Comparative Study on Non-Linear Analysis of In filled Frames for Vertically Irregular Buildings, International Journal of Engineering Science Invention, Volume 4, Issue 6, pp-42-51.

12. Malviya N., Pahwa S., 2017, Seismic Analysis of High Rise Building With IS Code 1893-2002 And IS Code 1893-2016, International Research Journal of Engineering and Technology, Volume: 04, Issue: 11, pp-2115-2119.

13. Mohod V. M., 2015, Effect of Shape and Plan Configuration On Seismic Response Of Structure, International Journal Of Scientific \& Technology Research, Volume-4, Issue-09, pp-84-88.

14. Natarajan S., Veeraragavan S., 2016, A Review on Analysis and Design of Shear Walls in High Rise Irregular Building, Internationa Journal of Scientific engineering and Technology Research, Vol-05, Issue-05, pp-808-815.

15. Redd R. K., Rao M. V. S., 2016, Seismic Analysis of High Raised Building by Response Spectrum Method, International Journal of Advanced Technology and Innovative Research, Vol-08, Issue-21, pp-4111-4118.

16. Singh R., Singh K. V., 2018, Analysis of Seismic Loads acting on multi-storey Building as per IS: 1893-2002 and IS: 1893-2016 :- A comparative Study, Journal of Civil Engineering and Environmental Technology, Volume: 04, Issue: 05, pp-405-408.

17. Anwade B. A., Aher B. S., Barate D. A., Raghuvanshi S. \& Kuralkar S., 2018, Seismic Analysis, Design and Comparative Study of RC Structure Using Different Codes, International Research Journal of Engineering and Technology, Volume: 05, Issue: 04, pp-4984-4990.

18. Gaikwad S. P., Tolani K. K., 2015, Study Of Dynamic Effect On Unsymmetrical Building (Rcc \& Steel), International Journal of Research in Engineering \& Advanced Technology, Volume 3, Issue 3, pp-104-109.

19. Rahman A.S., Deshmukh G., 2013 "Seismic Response of vertically Irregular RC Frame with Stiffness Irregularity at Fourth Floor" International Journal of Emerging Technology and Advanced Engineering, Volume 3, Issue 8, pp-377-385.

20. BIS 1893 (Part 1): 2016 Code of Criteria for Earthquake Resistant Design of Structures.

21. BIS 456:2000 Code of Practice for Plain and Reinforced Concrete.

22. BIS 800:2000 Code of Practice for general Construction in Steel.
Published By:

Blue Eyes Intelligence Engineering \& Sciences Publication

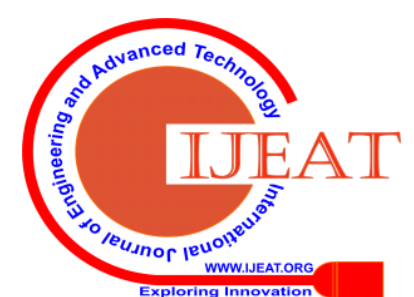


23. BIS 875 (Part 1): 1987 Code of Practice for Design loads (other than earthquake) for buildings and structures Part 1 Dead loads.

24. BIS 875 (Part 2): 1987 Code of Practice for Design loads (other than earthquake) for buildings and structures Part 1 Imposed loads.

25. BIS 875 (Part 2): 1987 Code of Practice for Design loads (other than earthquake) for buildings and structures Part 5 Special Loads and load combination.

26. BIS 13920:2016 Code of Practice for Ductile Design and Detailing of Reinforced Concrete Structures Subjected Seismic forces

\section{AUTHORS PROFILE}

Lovneesh Sharma1, Research Scholar, Civil Engineering Department, Chandigarh University Gharaun , Mohali (Punjab), India lovneeshsharma39@gmail.com

Swati Pathak ${ }^{2}$, Mtech, Civil Engineering Department, Shimla University, Shimla (H.P) Indiapathak.swati06@gmail.com 